\section{Oxygen Saturation in the Dental Pulp of Maxillary Premolars in Different Age Groups - Part 1}

Carlos Estrela ${ }^{1}$ Giuliano C. Serpa ${ }^{1}$, Ana Helena G. Alencar ${ }^{1}$, Kely F. Bruno ${ }^{1}$, Fernando B. Barletta ${ }^{2}$, Wilson T .Felippe ${ }^{3}$, Cyntia R.A. Estrela ${ }^{4}$, João B Souza ${ }^{1}$

\author{
'Dental School, UFGO - Universidade \\ Federal de Goiás, Goiânia, GO, Brazil \\ ${ }^{2}$ Dental School, ULBRA - Universidade \\ Luterana do Brasil, Canoas, RS, Brazil \\ ${ }^{3}$ Dental School, UFSC - Universidade \\ Federal de Santa Catarina, \\ Florianópolis, SC, Brazil \\ ${ }^{4}$ Dental School, UNIC - Universidade \\ de Cuiabá, Cuiabá, MT, Brazil
}

Correspondence: Prof. Carlos Estrela, Praça Universitária, s/n, Setor Universitário, 74605-220 Goiânia, GO, Brasil. Tel: +55-62-3209-6053. email:estrela3@terra.com.br
The aim of this study was to determine oxygen saturation levels in the dental pulp of maxillary premolars in different age groups. A total of 120 human maxillary premolars with normal dental pulps were selected covering the following age groups: 20-24, 25$29,30-34,35-39$ and $40-44$ years ( $n=24$ each group). 0xygen saturation was assessed using pulse oximetry. Analysis of variance was used to assess differences in oxygen saturation levels and Tukey's test was used to identify the age groups that differed from each other. Significance was set at 0.05 . Mean oxygen saturation of 120 premolars was $86.20 \%$ considering all age groups. Significantly reduced levels were found in the oldest group compared to the other groups: 40 to 44 years $-80.00 \%$ vs. $89.71,87.67,88.71$, and $84.80 \%$ for age groups $20-24,25-29,30-34,35-39$ years, respectively. The mean oxygen saturation levels were similar between 20 and 39 years of age $(86.20 \%)$ in the whole sample, but reduced significantly in the 40-44-year age group, suggesting that older patients present lower oxygen saturation results even in the absence of pulp tissue injury.
Wey W: oxygen saturation pulp vitality, sensibility test, dental pulp, diagnosis.

\section{Introduction}

Aging causes changes to the dentin-pulp complex, leading to natural decreases in cell density, blood supply, lymphatic drainage, and nerve supply. As a result, the volume of the pulp chamber and root canal progressively decrease. These factors affect the reparative capacity of the pulp, which may compromise your condition with aging (1).

In fact, it have been shown that sensibility tests do not accurately determine pulpal condition, irrespective of age, as they are based on vasoconstriction or vasodilation and sensitization of nerve fibers and are therefore incapable of providing precise information on pulpal blood flow (2-4). Moreover, age-related changes to the morphophysiological characteristics of the dental pulp may induce false-negative responses to thermal and electric pulp sensibility tests, as a result of increased dentin thickness, presence of pulp calcifications and other biological changes $(2,3)$.

Considering the need to overcome the limitations of dental pulp sensibility tests (thermal and electric), new diagnostic tools have been proposed to determine pulp vitality. Among these new options, pulse oximetry has been incorporated to endodontic practice, constituting a method noninvasive, painless and reliable (2-15).

The knowledge of the process of oxygen saturation $\left(\mathrm{SaO}_{2}\right)$ in the arterial blood $(2,3,15-20)$ allows to understand the importance of the application of this diagnostic recourse in determining the dental pulp vitality. Nitzan et al. (6) reported that the total oxygen in blood includes the hemoglobin-bound oxygen (97\%-98\%) and the oxygen dissolved in plasma (since hemoglobin is that allows the transfer of oxygen from the lungs to tissue cells). The level of arterial hemoglobin oxygenation is assessed by oxygen saturation in arterial blood $\left(\mathrm{SaO}_{2}\right)$, which is the ratio of oxygenated hemoglobin concentration $\left[\mathrm{HbO}_{2}\right]$ to total hemoglobin concentration in the blood $\left(\left[\mathrm{HbO}_{2}\right]+[\mathrm{Hb}]\right)$ $(6,16,17)$. When hemoglobin is fully saturated with oxygen it is called oxyhemoglobin $\left(\mathrm{HbO}_{2}\right)$, and when it release oxygen, it is reduced and called deoxyhemoglobin $(\mathrm{Hb})$. These two forms of hemoglobin absorb different amounts of light at different wavelengths (19). Pulse oximeters measure arterial oxygen saturation $\left(\mathrm{SaO}_{2}\right)$ in the dental pulp through a probe containing two diodes that emit light in two wavelengths, one in the red spectrum (approximately $660 \mathrm{~nm}$ ) and the other in the infrared spectrum (approximately $940 \mathrm{~nm}$ ). These emissions are captured by a photodiode receptor and converted by electronic circuits into $\mathrm{SaO}_{2}$ and pulse rates $(2,15-18)$.

Pulp oximetry has been used to determine $\mathrm{SaO}_{2}$ levels in healthy dental pulps, with mean values ranging from 75 to $94 \%(3-5,8,12-15)$ for different tooth groups, in different age groups. A recent critical review involving $\mathrm{SaO}_{2}$ levels revealed the following mean results: $87.73 \%$ for central incisors, 87.24\% for lateral incisors, and 87.26\% for canines (8). Conversely, the relationship between age and $\mathrm{SaO}_{2}$ levels in posterior teeth has been little explored. The aim of this study was to determine $\mathrm{SaO}_{2}$ levels in the normal dental pulp of maxillary premolars in different age 
groups using pulse oximetry.

\section{Material and Methods}

\section{Subject Selection}

This in vivo study included 120 healthy maxillary premolars from 100 patients treated at the endodontic clinic of the Dental School of the Universidade Federal de Goiás (Goiânia, GO, Brazil). Patients were selected through convenience sampling so as to form five groups $(n=24)$, according to the following age groups: 20-24, 25-29, 30$34,35-39$ and $40-44$ years.

Inclusion criteria were: teeth with intact crowns (no caries, restorations or fractures, no dental wear), absence of periodontal disease and absence of internal/external root obliteration or resorption. Smokers, patients with a history of systemic vascular or cardiovascular disease, occlusal or dental trauma and patients using systemic medications were excluded.

The present study was approved by the local institutional Research Ethics Committee. All the patients signed an informed consent form prior to the performance of any study procedures.

\section{Sample Calculation}

Sample size was calculated considering a confidence level of $95 \%(z=1.96)$, a margin of error of $\leq 2 \%$ and a standard deviation of 5 , which resulted in a sample (n) of 24 teeth for each age group. Selected teeth were assessed using a cold sensibility test and pulse oximetry.

\section{Cold Sensibility Test}

After the initial $\mathrm{X}$-ray image acquisition, used as a diagnostic aid, cold sensibility tests were performed by an endodontist. Teeth were isolated with cotton rolls and a saliva ejector. Then, Green Endo-Ice spray $\left(-26.2{ }^{\circ} \mathrm{C}\right.$, Hygenic Corp., Akron, OH, USA) was applied to the middle third of the buccal surface of the teeth using a cotton ball and a tweezer. Patients were asked to rate the intensity of sensitive stimuli (pain) using a 0-10-point scale, where $0=$ no pain and $10=$ severe pain. Score 0 was defined as a negative response after $15 \mathrm{~s}$ of spray application. When this occurred, the test was repeated 2 min after the first one.

\section{Pulse Oximetry}

$\mathrm{SaO}_{2}$ levels were determined using the $\mathrm{BCl} 3301$ handheld pediatric pulse oximetry monitoring system (Smiths Medical PM Inc., Waukesha, WI, USA), equipped with 3025 (for teeth) and 3026 (for fingers) sensors. All tests were performed by an endodontist. Teeth were isolated with cotton rolls, a saliva ejector and no dental reflector lamp. The probe was coupled to a device developed specifically for testing premolars, with the objective of placing the two diodes in parallel, so as to allow correct measuring of $\mathrm{SaO}_{2}$ levels in the dental pulp. A stainless steel adapter was fabricated specifically for this study (Fig 1 ). $\mathrm{SaO}_{2}$ levels were measured twice, i.e., the first time $30 \mathrm{~s}$ after adapting the probe to the tooth, and the second time $30 \mathrm{~s}$ after the first reading; the mean of the two measurements was used as the final result. A third measure was taken by placing the probe on the patient's index finger, to determine $\mathrm{SaO}_{2}$ levels in their blood.

All vitality tests were performed by a same professional, specialist in endodontics with more than 10 years of experience, with previous training in $10 \%$ of the sample.

\section{Statistical Analysis}

Analysis of variance (ANOVA) was used to assess differences in $\mathrm{SaO}_{2}$ levels between the age groups. Whenever differences were detected, Tukey's multiple comparison test was performed to identify the age groups that differed from each other. All results showing $p<0.05$ $(\alpha=5 \%)$ were considered significant.

\section{Results}

All the teeth assessed responded positively to the cold sensibility test. The overall mean $\mathrm{SaO}_{2}$ level obtained in the dental pulps was $86.2 \%$ (range: 69.0 to 99.0), lower than that found in the patients' index fingers (mean: 93.7\%; range: 70.0 to 99.0). Table 1 shows $\mathrm{SaO}_{2}$ levels obtained in the dental pulp of maxillary premolars according to age group. The 40-44-year age group differed statistically from the 20-24, 25-29, and 30-34-year groups $(\mathrm{p}<0.05)$ (Fig. $2)$, but showed similar results to the 35-39-year group $(p=0.122)$ (Table 2). However, this evidence is not sufficient to affirm that the group aged $35-39$ years was statistically
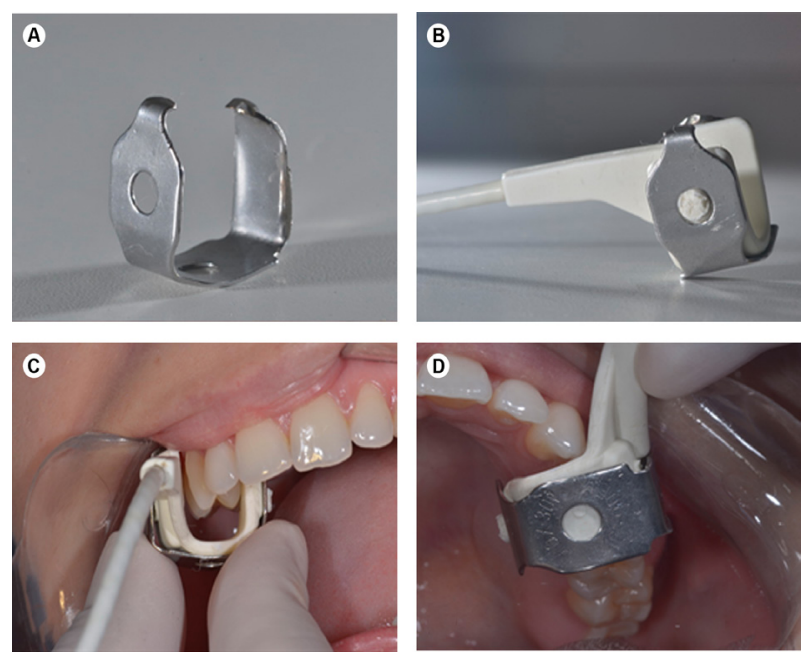

Figure 1. A-D: Stainless steel probe prepared to adapt the pulse oximeter to maxillary premolars. 
different from the others (Table 1). Even though the $\mathrm{SaO}_{2}$ results obtained in the 35-39-year age group did differ statistically from the other age groups, they did show a marked drop in $\mathrm{SaO}_{2}$, as can be viewed in Figure 2 .

Table 2. Differences between different age groups considering mean oxygen saturation levels measured in the dental pulp of maxillary premolars

\begin{tabular}{|c|c|c|c|}
\hline \multicolumn{2}{|c|}{ Age group (years) } & \multirow{2}{*}{$\begin{array}{c}\text { Difference } \\
2.04\end{array}$} & \multirow{2}{*}{$\frac{p \text { value }}{0.845}$} \\
\hline \multirow{4}{*}{$20-24$} & $25-29$ & & \\
\hline & $30-34$ & 0.99 & 0.987 \\
\hline & $35-39$ & 4.91 & 0.107 \\
\hline & $40-44$ & 9.71 & $0.000^{*}$ \\
\hline \multirow{4}{*}{$25-29$} & $20-24$ & -2.04 & 0.845 \\
\hline & $30-34$ & -1.04 & 0.985 \\
\hline & $35-39$ & 2.87 & 0.605 \\
\hline & $40-44$ & 7.67 & $0.002^{*}$ \\
\hline \multirow{4}{*}{$30-34$} & $20-24$ & -0.99 & 0.987 \\
\hline & $25-29$ & 1.04 & 0.985 \\
\hline & $35-39$ & 3.92 & 0.291 \\
\hline & $40-44$ & 8.71 & $0.000^{*}$ \\
\hline \multirow{4}{*}{$35-39$} & $20-24$ & -4.91 & 0.107 \\
\hline & $25-29$ & -2.87 & 0.605 \\
\hline & $30-34$ & -3.92 & 0.291 \\
\hline & $40-44$ & 4.80 & 0.122 \\
\hline \multirow{4}{*}{$40-44$} & $20-24$ & -9.71 & $0.000^{*}$ \\
\hline & $25-29$ & -7.67 & $0.002^{*}$ \\
\hline & $30-34$ & -8.71 & $0.000^{*}$ \\
\hline & $35-39$ & -4.80 & 0.122 \\
\hline
\end{tabular}

${ }^{*} \mathrm{p}<0.05$, Tukey's multiple comparison test.

Table 1. Oxygen saturation levels (\%) measured in the dental pulp of maxillary premolars according to age group $(\mathrm{n}=24$ each)

\begin{tabular}{lccccc}
\hline \multirow{2}{*}{$\begin{array}{l}\text { Age } \\
\text { group } \\
\text { (years) }\end{array}$} & \multicolumn{4}{c}{ Oxygen saturation (\%) } & Standard \\
\cline { 2 - 5 } & Minimum & Maximum & Median & Mean & error \\
\hline $20-24$ & 76.00 & 99.00 & 90.75 & 89.71 & 1.50 \\
$25-29$ & 70.00 & 99.00 & 87.00 & 87.67 & 1.55 \\
$30-34$ & 73.50 & 98.50 & 90.00 & 88.71 & 1.26 \\
$35-39$ & 72.50 & 96.00 & 85.25 & 84.80 & 1.58 \\
$40-44$ & 69.00 & 90.50 & 79.50 & 80.00 & 1.10 \\
\hline
\end{tabular}

\section{Discussion}

This study was conducted to determine oxygen saturation levels in the normal dental pulp of maxillary premolars in different age groups. The mean $\mathrm{SaO}_{2}$ level found in the dental pulps of maxillary premolars considering the whole sample was $86.20 \%$, lower than the levels measured in the patients' index fingers (93.70\%). The mean results obtained for the different age groups were as follows: $89.71,87.67,88.71,84.80$ and $80.00 \%$ for age groups $20-24,25-29,30-34,35-39$ and $40-44$ years, respectively. The oldest group (40-44) showed significantly lower $\mathrm{SaO}_{2}$ levels when compared to the other groups, and the 35-39-year group also showed a marked drop in $\mathrm{SaO}_{2}$ readings, however at a non-significant difference.

Precise diagnosis of pulp tissue conditions remains a challenge in endodontic practice, as the dental pulp is located inside a cavity and, consequently, inaccessible to direct inspection $(2,3,9)$. In addition to anatomical aspects, dental pulp sensibility tests (thermal and electric) commonly used in clinical practice provide information on nerve stimulation only, not on pulpal blood flow (2-6).

In this context, the use of pulse oximetry to analyze the vascular conditions of pulp tissues has emerged as an interesting diagnostic recourse $(2-5,12,17-21)$. Different pulse oximetry sensors and techniques have been studied (5-13,19-20) with the aim of effectively diagnose pulpal conditions. However, before pulse oximetry can be used to detect dental pulp abnormalities in different clinical situations, reference $\mathrm{SaO}_{2}$ levels for normal/healthy dental pulps have to be determined (2,7-14).

In the present study, different $\mathrm{SaO}_{2}$ results were found in the dental pulps and index fingers of the patients. $\mathrm{A}$

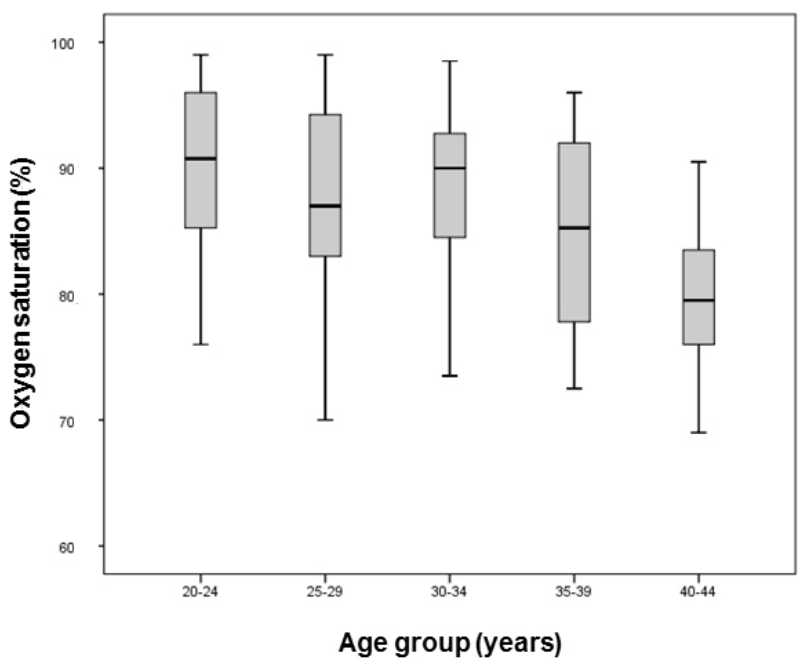

Figure 2. Distribution of oxygen saturation levels (\%) measured in the dental pulps of maxillary premolars according to age group. 
possible explanation for this difference could be dental pulp location, i.e., surrounded by hard tissues, which act as a physical barrier to the detection of vascularization and to the diffraction of light through enamel prisms and dentin, leading to lower readings in the oximeter $(1,2,5,22)$.

$\mathrm{Mean} \mathrm{SaO}_{2}$ level measured in premolar teeth in our study was $86.20 \%$, different from previous studies $(5,10,11)$. One important difference between our study is the larger sample size $(n=120)$ and the stratification of patients according to age groups. Age stratification aimed to determine whether $\mathrm{SaO}_{2}$ levels in teeth would vary with age and indeed revealed that $\mathrm{SaO}_{2}$ levels gradually decrease as age advances. In fact, this decrease reached statistical significance in our oldest age group, aged 40-44 years, where mean $\mathrm{SaO}_{2}$ was $80 \%$. This finding may be associated with age-related changes in the morphophysiological characteristics of the dentin-pulp complex, combined with a decrease in pulpal blood flow. Tranasi et al. (21) observed that the genetic changes underlie the histological modification of the dental pulp in aging. The authors reported that a significant reduction of the vitality in older dental pulp results from the gene expression, cellular and tissue development, cellular growth and proliferation charts. These data are $\vec{s}$ confirmed by the higher expression of growth factors like bone morphogenetic protein, TGFA, growth factor differentiation family, platelet-derived growth factor $\alpha_{\text {, }}$ vascular endothelial growth factor $\alpha$, and FGF family in young dental pulp.

Aging leads to the deposition of mineralized tissue in the pulp chamber and root canal walls. During root formation, dentinal deposition occurs as part of the physiological processes of aging, due to the continuous secretion of dentin matrix by odontoblasts (22). This progressive reduction of the dental pulp space is the most evident morphological change associated with aging (23). In addition, physiological changes also take place in the pulp, i.e., blood vessels show arteriosclerotic changes, potentially causing accumulation of mineral deposits on the inner walls of arterioles (24). All these data seem to contribute to the lower levels of $\mathrm{SaO}_{2}$ obtained in older people, as pointed out in previous studies $(9,10,13)$.

Age-related decreases in $\mathrm{SaO}_{2}$ levels in pulp tissue have been reported before. According to Stella et al. (13), the mean $\mathrm{SaO}_{2}$ reading for normal maxillary central incisors in a sample of children/adolescents (7-13 years old) was higher than the mean reading obtained in a sample of adults (22-36 years old), with 84.35 vs. $77.88 \%$, respectively. Bargrizan et al. (25) measured $\mathrm{SaO}_{2}$ levels in open-apex teeth and found a mean of $86.71 \%$ in left central, $86.83 \%$ in right central, $84.50 \%$ in left lateral, and $83.35 \%$ in right lateral incisors. The same authors also assessed teeth with closed apices, observing the following results: $84.61 \%$ in left central, $85.00 \%$ in right central, 83.14\% in left lateral, and $81.82 \%$ in right lateral incisors. Giovanella et al. (12) used pulse oximetry to determine the level of $\mathrm{SaO}_{2}$ in the dental pulp of intact permanent teeth with periodontal attachment loss and gingival recession. The authors found a correlation between periodontal disease and lower $\mathrm{SaO}_{2}$ values in the pulp.

To increase the reliability of the study, we only included patients with intact crowns, absence of periodontal disease, normal probing depth, absence of gingival recession, and absence of root obliteration/resorption. These inclusion criteria aimed at eliminating any factors that could affect pulp status. Also, our exclusion criteria were determined so as to exclude any clinical conditions that might impair or limit the use of pulse oximetry, e.g., patients with high venous pressure, cardiovascular diseases, low peripheral perfusion, or hypotension (7). Finally, teeth with a history of occlusal or traumatic dental injury were excluded due to the potential presence of pulp tissue alterations, which could lead to less effective or false-negative responses to pulse oximetry $(2,3,5,7,9-15,20)$.

In order to obtain more reliable readings with pulse oximetry, through the parallelism of both light-emitting diodes, we developed a device to specifically fit maxillary premolars. Several studies unanimously state that pulse oximeters should be adapted to fit properly on the patients' teeth, since they have been developed to measure $\mathrm{SaO}_{2}$ in fingers $(3,5,7-9,11-13)$. The accuracy of the pulse oximeter to evaluated de $\mathrm{SaO}_{2}$ levels may be associated with equipment calibration.

Dentists should be alert to age-related dental pulp alterations, so that they can establish an accurate diagnosis and precise treatment plan to achieve the most favorable outcomes, avoiding premature and unnecessary interventions. Thermal and electric tests and even cavity tests may yield false-negative results in older individuals. Thus, the association of sensibility and vitality tests seems to be a sensible alternative to determine clinically the pulpal condition.

In summary, the present study advances the current body of knowledge by determining mean $\mathrm{SaO}_{2}$ levels in the normal dental pulp of maxillary premolars in different age groups, with mean of $86.20 \%$. There was verified reduction significant in the 40-44-year age group, suggesting that older patients present lower oxygen saturation results even in the absence of pulp tissue injury.

\section{Resumo}

Este estudo determinou os níveis de saturação de oxigênio ( $\mathrm{SaO} 2)$ em polpas dentárias de pré-molares superiores em diferentes faixas etárias. Foram selecionados 120 pré-molares superiores humanos com polpas dentárias normais, abrangendo os seguintes grupos etários: 20-24, 25-29, 30-34, 35-39 e 40-44 anos ( $n=24$ para cada grupo). A saturação de oxigênio foi 
avaliada utilizando oximetria de pulso. A análise de variância foi utilizada para avaliar diferenças nos niveis de saturação de oxigênio, e o teste de Tukey foi utilizado para identificar os grupos etários que diferiam uns dos outros. A significância foi estabelecida em 0,05 . A saturação média de oxigênio foi de $86,20 \%$ considerando todos os grupos etários. Niveis significativamente reduzidos foram encontrados no grupo de individuos de maior idade em comparação aos outros grupos: 40 a 44 anos - 80,00\% vs. $89,71,87,67,88,71$ e $84,80 \%$ para os grupos etários $20-24,25-29$, 30-34, 35-39 anos. Os niveis médios de saturação de oxigênio foram semelhantes entre os 20 e os 39 anos de idade $(86,20 \%)$, mas reduziramse significativamente na faixa etária de 40-44 anos, sugerindo que os pacientes mais idosos apresentam menor saturação de oxigênio mesmo na ausência de lesão do tecido pulpar.

\section{Acknowledgements}

The authors have no conflicts of interest to declare concerning publication of this manuscript. This study was supported in part by grants from the National Council for Scientific and Technological Development (CNPq \#306394/2011-1 to C.E.).

\section{References}

1. Murray PE, Stanley HR, Matthews JB, Sloan AJ, Smith AJ. Age-related odontometric changes of human teeth. Oral Surg Oral Med Oral Pathol Oral Radiol Endod 2002;93:474-482.

2. Jafarzadeh $\mathrm{H}$, Rosenberg PA. Pulse oximetry: review of potential aid in endodontic diagnosis. J Endod 2009;35:329-333.

3. Gopikrishna V, Pradeep G, Venkateshbabu N. Assessment of pulp vitality: a review. Int J Pediatr Dent 2009;19:3-15.

4. Mejàre IA, Axelsson $S$, Davidson $T$, Frisk $F$, Hakeberg $M$, Kvist $T$, et al.. Diagnosis of the condition of the dental pulp: a systematic review. Int Endod J 2012;45:597-613.

5. Gopikrishna $V_{1}$ Tinagupta $K$, Kandaswamy D. Evaluation of efficacy of a new custom-made pulse oximeter dental probe in comparison with the electrical and thermal tests for assessing pulp vitality. J Endod 2007;33:411-414.

6. Nitzan M, Romen A, Koppel R. Pulse oximetry: fundamentals and technology update. Med Dev: Evid Res 2014;7:231-239.

7. Calil $\mathrm{E}$, Caldeira $\mathrm{CL}$, Gavini $\mathrm{G}$, Lemos EM. Determination of pulp vitality in vivo with pulse oximetry. Int Endod J 2008:41:741-746.

8. Bruno KF, Barletta FB, Felippe WT, Silva JA, Alencar AHG, Estrela C. Oxygen saturation in the dental pulp of permanent teeth: a critical review. J Endod 2014;40:1054-1057.

9. Pozzobon MH, Vieira RS, Alves AM, Reyes-Carmona J, Teixeira CS, de Souza BD, et al.. Assessment of pulp blood flow in primary and permanent teeth using pulse oximetry. Dent Traumatol 2011;27:184188.
10. Dastmalchi N, Jafarzadeh H, Moradi S. Comparison of the efficacy of a custom-made pulse oximeter probe with digital electric pulp tester, cold spray, and rubber cup for assessing pulp vitality. J Endod 2012;38:1182-1186.

11. Setzer FC, Kataoka SH, Natrielli F, Gondim-Junior E, Caldeira CL. Clinical diagnosis of pulp inflammation based on pulp oxygenation rates measured by pulse oximetry. J Endod 2012;38:880-883.

12. Giovanella LB, Barletta FB, Felippe WT, Bruno KF, Alencar AHG, Estrela C. Assessment of oxygen saturation in dental pulp of permanent teeth with periodontal disease. J Endod 2014;40:1927-1931.

13. Stella JPF, Barletta FB, Giovanella LB, Grazziotin-Soares R, Tovo MF, Felippe WT, et al.. Oxygen saturation in dental pulp of permanent teeth: difference between children/adolescents and adults. J Endod 2015;41:1445-1449.

14. Schnettler JM, Wallace, JA. Pulse oximetry as a diagnostic tool of pulpal vitality. J Endod 1991;17:488-490.

15. Mills RW. Pulse oximetry-a method of vitality testing for teeth? $\mathrm{Br}$ Dent J 1992;172:334-335.

16. Farmer J. Blood oxygen measurement. In: Webster JG, ed. Design of Pulse Oximeters. Bristol: Institute of Physics; 1997:21-39.

17. Wagner PD. Ventilation, blood oxygen and gas exchange. In: Mason RJ, Broaddus VC, Murray JF, Nadel JA. Murray and Nadel's Textbook of Respiratory Medicine. Philadelphia: WB Saunders: 2005.

18. Cerqueira MG. Desenvolvimento de um sensor de determinação da vitalidade dentária. Master's dissertation. Coimbra: Universidade de Coimbra; 2013.

19. Schratz WW. Pulse oximetry: a review, with emphasis on applications in dentistry. Anesth Prog 1987;34;100-101.

20. Samraj RV, Indira R, Srinivasan MR, Kumar A. Recent advances in pulp vitality testing. Endodontol 2003;15:14-19.

21. Tranasi M, Sberna MT, Zizzari V, D'Apolito G, Mastrangelo F, Salini L, et al.. Microarray evaluation of aged-related changes in human dental pulp. J Endod 2009;35:1211-1217.

22. Stanley $H R$, White $C L$, McCray L. The rate of tertiary (reparative) dentin formation in the human tooth. Oral Surg Oral Med Oral Pathol 1966;21:180-189.

23. Morse DR. Age-related changes of the dental pulp complex and their relationship to systemic aging. Oral Surg Oral Med Oral Pathol 1991;72:721-745.

24. Ikawa M, Komatsu H, Ikawa H, Mayanagi H, Shimauchi H. Age-related changes in the human pulpal blood flow measured by laser Doppler flowmetry. Dent Traumatol 2003;19:36-40.

25. Bargrizan $M$, Ashari MA, Ahmadi $M$, Ramezani J. The use of pulse oximetry in evaluation of pulp vitality in immature permanent teeth. Dental Traumatol 2016; 32:43-47. 